\title{
Semantic and Metasemantic Notions of Analyticity
}

\author{
Artur Ravilevich Karimov $^{1} \&$ Valentina Alexandrovna Kazakova ${ }^{2}$ \\ ${ }^{1}$ Kazan Federal University, Russian Federation \\ ${ }^{2}$ Kazan State University of Architecture and Engineering, Russian Federation \\ Correspondence: Artur Ravilevich Karimov, Kazan Federal University, 420008, Kremlevskaya 18, Kazan, \\ Russian Federation. E-mail: arrkarimov@kpfu.ru
}

Received: August 1, 2014 Accepted: August 18, 2014 Online Published: October 30, 2014

doi:10.5539/ass.v10n22p285 URL: http://dx.doi.org/10.5539/ass.v10n22p285

\begin{abstract}
In this article the evolution of main conceptions of analyticity is analyzed. Kant's criteria for analytic/synthetic distinction are discussed. Frege and Carnap notions of analyticity are set out. It is shown that Frege and Carnap shifted the criteria of analyticity to the justificatory status of judgments. The notion of truth in virtue of meaning and its criticism is exposed. Critical arguments against analyticity by W. V. O. Quine are discussed. Williamson's arguments against traditional notions of analyticity are formulated. Williamson maintains that analytic truths are reduced to truths of other base classes-necessary, semantic or logical. It is shown that the stipulative definition of analyticity is vulnerable to Williamson's argument. Russell's conception of truth in virtue of reference determiner is exposed and evaluated. It is defended that the notion of truth in virtue of reference determiner is immune to many standard objections against analyticity.
\end{abstract}

Keywords: analyticity, meaning, stipulation, reference

\section{Introduction}

Analyticity is one the most controversial concepts in the history of analytic philosophy. It became the center of the debate in the middle of XXth century. Despite the defense of analyticity from such prominent philosophers as Grice, Strawson and Putnam, for a long time after Quine's "Two dogmas" it was considered at best useless. In the last few years, however, there was a resurgence of interest in analyticity. We will concentrate on three different sources: the critical account of analyticity by a prominent British philosopher T. Williamson (2008) and two proponents of analyticity-G. Russell (2008), and C. Juhls and E. Loomis (2010). The purpose of the article is to trace the key steps of development of the notion of analyticity from Kant to our time and determine whether this development was in effect successful. In case of analyticity it is especially important to expose the history of the notion, because different philosophers had different conceptions of analyticity. So when someone uses the word "analyticity" it is not always clear what particular conception of analyticity is implied. As we will show, historically, the notion of analyticity is a semantic notion. Semantic notions have something to do with meaning and reference. And we will see that the history of analyticity was a gradual evolution from accent on meaning to accent on reference (reference determiner). We will examine some of the objections against analyticity and will see how different theories of analyticity deal with these objections. The notion of analyticity as truth in virtue of meaning met with some powerful objections in the XXth century. The main objection raised by Boghossian (and later Williamson) was that no truth is true only in virtue of meaning. We will examine two main strategies which were proposed to counter this objection. One strategy is metasemantic which consists in defining analyticity in terms of stipulation (Juhl and Loomis). The other strategy we will call the semantic strategy which consists in redefining the concept of meaning within the framework of extensional semantics to include the referent and reference determiner (Russell). Ultimately, we want to determine which theory of analyticity is the least vulnerable to the main objections.

\section{Main Part}

The notion of analyticity became the object for discussions in philosophy ever since it was introduced by Kant. Kant famously offered 4 criteria of analytic judgments (see Proops, 2005; Hanna, 2007). First, that the predicate of the sentence must be covertly contained in the subject. Second, that the subject and predicate of the sentence must be identical. Third, that it is contradictory to negate the predicate. Fourth, that analytic judgments clarify; they do not expand our knowledge. The examples offered by Kant are: "all bodies are extended in space" and 
"gold is yellow metal". It is worthy of note that Kant's criteria for analyticity are not consistent with each other. For example, explicit tautologies, like "gold is gold", fit first through the third criteria, but don't fit fourth. Also, Kant seems to apply analyticity only to judgments of subject-predicate form. So if we take the sentence "If Socrates is mortal, Socrates is mortal", it would not be considered analytic by Kant's criteria. He explicitly distinguished between categorical, conditional and disjunctive sentences. It is not clear which of the criteria is more important. Some authors claim that it is the containment criterion and others that it is the contradiction criterion (Anderson, 2005; Proops, 2005). The containment metaphor itself is very ambiguous. What does it mean that the predicate is contained in the subject? It is subjectively determined or not? It seems that Kant himself thought of containment as a relation of two notions when one is contained in the logical extension of another. Since for Kant logical extension refers to notions (not objects), therefore the notion of "gold" is contained under the notion of "metal". But what guarantees that a notion is contained under the other? Unless we are willing to accept some kind of essential and necessary relation between objects, this form of containment is at least subjective. Of course, Kant was not willing to accept any kind of essences and famously defended that things-in-themselves are unknowable. Interestingly, in Kant's example he uses the empirical notion of "gold" which is clearly acquired a posteriori. Kant thought that we may have some analytic knowledge of objects which are known through experience. The problem with the empirical notions is that it is not at all clear whether their predicate is contained in the subject. Take the sentence "Water is $\mathrm{H}_{2} \mathrm{O}$ ". It seems analytic and fitting all the criteria. But it is such only after the 18th century when the molecular structure of water was discovered. The other problem is that a lot of empirical knowledge is testimonial, so we refer to experts who guarantee that the predicate and the subject are one and the same thing. But for those who accept the testimony of experts it is not at all clear that it should be so. For someone who never conducted the appropriate experiment in chemistry class "Water is $\mathrm{H}_{2} \mathrm{O}$ " could be just as good as "Water is $\mathrm{H}_{3} \mathrm{O}$ " or "Water is $\mathrm{H}_{4} \mathrm{O}$ ", as long as someone told them so and they were gullible enough to accept it. It is understandable why Kant didn't have a very clear notion of analyticity. For him, the most important were synthetic a priori judgments.

Moving forward, we must make a brief discussion of analyticity as understood by Frege and Carnap, because they were transitional to modern discussions about analyticity (see Dummet, 1991; Rey, 2013). Frege criticized the notion that analytic judgments can be mere covert or explicit tautologies. While for Kant all analytic judgments are definitions, Frege distinguished what he called Definition and Erklärung (real definition). Definition is concise denotation. This is a logical procedure which does not introduce new knowledge, e.g. "a straight line is the shortest line between two dots". On the contrary, in real definitions we fix the referent each time differently. Real definitions change, expand, become richer. To give a new definition is to take a different look at the object. Therefore, though definitions are analytic judgments they are by no means trifling propositions, as Locke would say. Definitions can be based on experiential basis, i.e. a posteriori, or have conceptual origin, i.e. a priori. In natural sciences no investigation would help us to deduce from the notion of a physical object any predicates analytically. For mathematics the story is different. The initial postulates of mathematics are introduced conventionally; therefore, they themselves and deductions from them are purely analytic. Interestingly, for Frege arithmetic was analytic, but geometry was synthetic. The definition of analytical judgment for Frege is that it should follow from definitions or laws of logic. This means that analytic judgments are either definitions or logical truths. This definition of analyticity is what later was called Frege-analyticity. The main result of this definition is the shift from epistemic role of analytic judgments, as it was with Kant, to their justificatory status. If a judgment is justified without recourse to experience it is analytic. Otherwise, it's synthetic. In other words, synthetic judgments are about the world, while analytic judgments are about concepts.

Initially, Carnap supported Fregean notion of analyticity and subsumed analytic truths under the category of logical truths (see Carnap, 1928, 1947; Friedman, 1999). This he called the syntactic notion of analyticity, because analytic truths are deduced from sentences by rules of logical syntax alone. Already in his "Logical syntax" Carnap introduced the notions of L-analyticity and P-analyticity. L-analytic sentences are Frege-analytic, while P-analyticity corresponds to physical analyticity. P-analytic sentences contain not only logical terms, but also descriptive terms, e.g. "gas volume increases in proportion to its temperature". But his key work is "Empiricism, semantics and ontology". In this work a purely semantic notion of analyticity is established. The main concept which he discusses is the concept of linguistic framework. He distinguishes between two types of questions: questions within the given linguistic framework and questions about the linguistic framework itself. The example of the first kind would be "Is there a prime number after 100?" To answer this question we only need to defer to our theory of numbers. To this he contrasts the question "Are there numbers?" Here we don't have any theory to defer to, so this question becomes meaningless. How does that affect the notion of analyticity? Within a given framework a sentence can be analytic while within the other framework it would be synthetic. Take the law of contradiction itself-that $p$ and not-p cannot be true together. It is analytic within the framework 
of classical logic and not analytic within the framework of intuitionist logic. This relativizes analyticity against a particular linguistic framework. To this Carnap adds the notion of meaning postulates. A truth based on a meaning postulate is different from a logical truth. The example of a logical truth would be "All bachelors are bachelors". The example of a truth based on a meaning postulate would be "All bachelors are married". In the latter sentence you only need to know the meaning of the word "bachelor" to agree with this sentence. These sentences are true in virtue of meaning alone. Carnap formulated the "traditional" definition of analyticity - truth in virtue of meaning.

The notion of truth in virtue of meaning was subject to harsh criticism, particularly, by W. V. O. Quine in his "Two dogmas of empiricism" (Quine, 1951). Let's examine briefly what the criticism was about. Quine had two lines of criticism against analyticity. The first one is to show that the notion of analyticity as truth in virtue of meaning alone is meaningless. The second line, which he adopted later, was to admit some form of analyticity but claim that it has no real value for epistemology. There are several objections which were raised against analyticity by Quine but the most important is the argument from holism. The argument from holism consists in denying any special status to a particular sentence within the web of belief. If we have a very strong theory and a fact which contradicts that theory, we can either ignore the fact or change the theory. Suppose there is someone who has never met any swans, but white. Suppose, he is presented with a black swan. Should he change his opinion about swans? Not necessarily. He could just as well name black swans "bswans" and say that it is a whole new species of birds. What about the sentence "All swans are white"? Is it analytic or synthetic? They are both, on Quine's account. How bad is this for the theory of analyticity? We would say that this is a good argument for not accepting any of the empirical sentences (based on observation and containing natural kind terms) as analytic. But with this provision the theory of analyticity still stands against this particular objection. The second important objection, raised by Boghossian, is that no judgment can be true solely in virtue of meaning (Boghossian, 1996). It has to be true in virtue of what the world is like, too. Take a simple tautology: "gold is gold". Usually, it is said this sentence is true in virtue of being a law of logic, namely the law of identity. But isn't it also true that in reality gold is gold, in reality things are identical with themselves. So, the sentence "gold is gold" is true not only in virtue of the law of logic, but in virtue of how things really are in the world, even though its truth was already determined by the meaning of that expression.

A number of strategies were proposed to counter this argument, but the best strategy was outlined by G. Russell (2008). She distinguished between different kinds of determination. They are full determination, conjoint determination, partial determination and redundant determination. For our purposes we will not examine this distinction in detail. Just as an example, the sentence "Today's temperature is 30 degrees Farenheit" is fully determined by what the world is like. But the sentence "gold is gold" is only redundantly determined by what the world is like. To be redundantly determined is to be determined by something when it is already determined by someone else. To explain this, we can borrow "the chip in the head" example from the discussion about free will and slightly modify it. Suppose there are two hunters who simultaneously shoot and kill a duck. Each of the shots would have killed the duck, so we can say that the other shot was redundant. Thus, we can say that the fact that the duck was killed was redundantly determined by the shot of the hunter $\mathrm{X}$, because the hunter $\mathrm{Y}$ has already made a successful shot. If the hunter X didn't shoot for some reason, the hunter Y would have killed the duck. To convert this example for our purposes, we can say that the sentence "gold is gold" is redundantly determined by the world.

Even if there is a meaningful notion of analyticity it is not clear whether it has any use in epistemology. Kant recognized analytic judgments, but he denied that they can serve any purpose for cognition. In the following paragraphs we will examine some criticisms that deny any useful sense of analyticity. Quine himself later came to recognize that analytic sentences can be meaningful. He advanced the notion of stimulus-analyticity. A stimulus-analytic sentence is one which a subject would assent to in every relevant situation. This presupposes the community of speakers of a language. Stimulus-analytic sentences are behavioral reactions which come from dispositional character of consciousness. But this is a very weak notion for Quine, since it is just a behaviorist "ersatz" of the philosophical notion of analyticity. Stimulus-analyticity would apply to anything that most people would accent to, e.g. the sentence "There have been black dogs".

More recently some powerful objections against analyticity were advanced by T. Williamson (2008). Before we consider them, we have to explain the difference between metaphysical and epistemological analyticity, following Boghossian (1996). A sentence is said to be metaphysically analytic if it is true in virtue of meaning alone. By contrast a sentence is epistemologically analytic if anyone who understands it is justified in taking it to be true. The first one is a stronger sense of the term, while the second sense is weaker.

Let's consider some Williamson's arguments against metaphysical analyticity first. Williamson claims that there 
are no such truths as analytic truths. Any account of analyticity shifts the burden from explaining analyticity to explaining knowledge of some base class of truths: necessary, logical or semantic. Let's examine what he calls modal-analyticity. Modal-analytic truths are truths whose meaning is sufficient for truth. Are modal-analytic truths also necessary? If we take any necessary proposition, even an empirical one, its actual meaning will be sufficient for its truth, e.g. "water is H2O". So, we can call necessary truths modal-analytic, too. This, of course, does not mean that they are merely linguistic or conceptual. Water is really molecules of $\mathrm{H}_{2} \mathrm{O}$. But the connection between analyticity and necessity is not straightforward. Not all necessary truths are modal-analytic, e.g. "I am not Tony Blair". There are also contingent sentences that are modal-analytic, e.g. "It is raining if it is actually raining". If it wouldn't have been raining it wouldn't also have been actually raining. One could say that these examples are marginal and the core of philosophical truths is modal-analytic and necessary, but again this doesn't show why they should owe their truth to linguistic or conceptual meaning and not to some deep metaphysical necessity. Similarly, Frege-analyticity is based on the notion of logical truth. But logical truths are a separate kind of truths which are not in any way insubstantial or merely verbal. If some truth is logical, it doesn't mean that it poses no constraint on the world. As we have seen earlier with the notion of necessity, the notion of logical truth doesn't need the notion of analyticity to explain its truth. What if we defer to synonymy for explanation of analytic truths? Suppose, we have a clear notion of meaning and synonymy and we tried to explain analytic sentences as sentences with synonymous expressions. Here we face a problem with referential expressions which are synonymous on the standard theory of referential theory of meaning for proper names. If Hesperus and Phosphorus are synonymous, everyone should assent to the sentence "Hesperus is Phosphorus". But astronomically ignorant person would be in no position to know that Hesperus is Phosphorus even if he knows the meaning of the expressions "Hesperus" and "Phosphorus" individually. Therefore, synonymy would be a bad explaination for analyticity. It seems that the notions of necessity, logical truth and synonymy together and individually cannot explain analyticity.

If the metaphysical notion of analyticity is so controversial, then may be a weaker notion of analyticity will be defensible? The epistemological notion of analyticity requires only that whoever hears an analytic sentence will assent to it. This notion explores the link between understanding a sentence and the disposition to assent to it. To this Williamson gives an example of logical truth which would typically cause someone to assent. The example is a sentence "every vixen is a vixen". Typically you would say that whoever understands this sentence assents to it. But there is a counterexample. Suppose, someone doesn't believe in vixens and at the same time believes that sentences with the universal quantifier are existentially committing. This person would not assent to this sentence on the ground that there are no vixens, so any sentence about vixens with the universal quantifier for that person would be false.

Juhl and Loomis proposed that the best case of analyticity would be explicit stipulative definition (Juhl \& Loomis, 2010). Suppose, we stipulate that 'frenchelor' is a French bachelor. First of all, no empirical evidence can count in favor or against the statement "Frenchelors are French bachelors". This statement is true and indefeasible and it is true in virtue of meaning alone. Also, the metalinguistic sentence "The sentence "All Frenchelors are French bachelors' is true" is also empirically indefeasible. The first objection to the stipulative definition of analyticity would be that it has no pragmatically useful role. Why would we need to introduce such terms as 'frenchelor'? In answer to this it can be said that even if this were true, it would have no bearing on whether there is a coherent notion of frenchelorhood. The fact that we have no useful role for the notion of "phlogiston" does not mean that we don't have a perfectly coherent notion of "phlogiston", or similarly, "witch". The next objection against stipulative definition of analyticity is again raised by Williamson and it is more powerful. To appreciate this objection we must make the distinction between semantic and metasemantic facts. Semantic facts are facts about meaning. That "Frenchelors are French bachelors" is semantics, but the fact that "Frenchelor" was introduced by someone saying "Frenchelors are French bachelors" is metasemantic. But, as Williamson shows, the act of stipulation makes the sentence true in a trivial way-it is standard contribution of meaning to truth. The fact that "water" in English was introduced to refer to water and " $\mathrm{H}_{2} \mathrm{O}$ " was introduced to refer to molecules of $\mathrm{H}_{2} \mathrm{O}$ does contribute to the truth of the sentence "Water is $\mathrm{H}_{2} \mathrm{O}$ ", but in a very trivial way. What is left? At best, our saying that "all Frenchelors are French bachelors" means that French bachelors are French bachelors, but that is a logical truth and we have seen that logical truths are a separate kind of truths. The stipulative meta-semantic notion of analyticity is a compromise in order to save the a priori status of analytic truths. In this sense, analytic judgments lose their substantial philosophical role and become what Locke called "trifling propositions". But analytic sentences need not be necessarily a priori as maintained in the classical definition of analyticity. As we will show, the concept of analyticity remains even if analytic judgments are a posteriori. This will require a substantive change in the notion of meaning which was made in the late XXth century by a number of philosophers mentioned below. 
A radical move was needed to save analyticity and this move was made by G. Russell. She distinguished four different components of meaning: content, character, reference determiner and extension (Russell, 2008). Difference between content and character is best seen in demonstratives: 'I', 'here', 'now'. Kaplan was first to make distinction between content and character (Kaplan, 1979). He identified content with Fregean sense, i.e. function from possible worlds to extensions. Character is a function from context to content. Character determines that in different contexts an utterance expresses different content. Character also plays another important role-it is a part of meaning that a speaker must know in order to be considered competent with the word. So, if content of ' $I$ ' is an agent of utterance, the character of 'I' is a rule for determining that content, given the context of an utterance. For sentences the content will be the proposition it expresses. Reference determiner is what fixes the referent of a term, it is a condition an object must meet in order to fall into the extension of an expression. For demonstratives it would be context of utterance, for predicates-the context of evaluation, for proper names-context of introduction of the term. For Russell, the sentence is analytic not in virtue of content or character, but reference determiner. It happens if "for all pairs of context of introduction and context of utterance, the proposition expressed by S with respect to those contexts is true in the context of evaluation" (Russell, 2008, p. 56). "Bachelors are unmarried men" will be a good candidate for analyticity on this account. The reference determiner for 'bachelor' is the condition that the objects which it applies to be male and unmarried in the context of evaluation. The reference determiner for proper names is the condition that it applies to the object which the baptizer demonstrated when first introducing the name. Does the notion of analyticity as truth in virtue of reference determiner avoid the above-mentioned arguments against analyticity? At the very least, it avoids all objections against the epistemic notion of analyticity, because one need not assent to analytic truths defined as true in virtue of reference determiner. Reference determiners need not be known to the subject who uses the term. It avoids the objection of shifting explanation to the notions of necessity and logical truth. It also avoids objections against synonymy, because "Hesperus is Phosphorus" would not be analytic in this sense, since "Hesperus" and "Phosphorus" would have different reference determiners. And it avoids the standard objection that no truth can be true solely in virtue of meaning by introducing the notion of redundant determination. This result is largely based in adoption of extensional semantics instead of intentional semantics which was used by Carnap and other logical positivists in early XXth century. If the extension becomes part of the meaning of the expression, then the reference determiner is also a part of the meaning. But both are independent of the epistemic status of the knower, therefore the knower doesn't have to have any a priori access to the truth of the expression.

The afore-mentioned Kaplan's distinction between content and character paved the way to two-dimensional approach to semantics. Two-dimensionalism is a theory based on possible-world semantics which adds a second dimension to meaning. Traditionally meaning and extension were tied to our actual world. A second dimension evaluates the expression against a counterfactual world. The sentence "I am the 44th president of the United States", uttered by Barack Obama is assessed not only by the context of utterance (in this case, the person pronouncing the sentence), but also by the circumstance of evaluation-which world is considered actual. In our world $\mathrm{W}_{0}$, considered as actual, this sentence is true. But in a world $\mathrm{W}_{1}$, where John McCain won the election, considered as actual, this sentence is false. The sentence "Water is $\mathrm{H}_{2} \mathrm{O}$ " is true if our world is taken as actual. But it is false in a world where water is XYZ, if that world is taken as actual. If we add actuality operator " $\mathrm{A}$ " we can construct necessary a posteriori truths, such as $\mathrm{A}$ (Water is $\mathrm{H}_{2} \mathrm{O}$ ). We have seen that the sentences containing indexicals, such as "I am here now", are always true in every context of evaluation. This means that their truth is established a priori. At the same time, this sentence is not cognitively insignificant and is a matter of empirical discovery. The same works for modal operators. How does this help with understanding analyticity? We have seen that Kripke severed the connection between analyticity, aprioricity and necessity. There is a way in which 2D-semantics helps to reinstall that connection. The idea is that we have a priori access to the reference-fixing criteria of the expressions in our language, but we only have a posteriori access to the modal profile of these expressions. This means that we can give a priori definitions to those terms the extension of which we don't understand (Lewis, 1970). This idea gives support to the whole concept of conceptual analysis, or so-called "armchair reasoning". However, 2D-semantics has been the object of harsh criticism for the last decade (Schroeter, 2012).

\section{Conclusions}

In this article we have examined different notions of analyticity, starting from Kant. We saw that Kant's criteria of analyticity, especially the containment metaphor, were criticized for subjectivity and vagueness. Frege defined analyticity as what follows from logic and definitions alone. For Frege the main criterion for analytic/synthetic distinction is the justificatory status of a proposition. Carnap relativized analyticity by introducing the notion of linguistic frameworks. With his notion of meaning postulates he also defended (what would later be called) a 
standard definition of analyticity as truth in virtue of meaning. The notion of truth in virtue of meaning became the object of sharp criticism from Quine. We saw that the objection from holism can be swallowed by admitting that all empirical sentences are synthetic. The argument that no truth can be true solely in virtue of meaning can be countered by the notion of redundant determination. We have considered Williamson's arguments against modal-analyticity and Frege-analyticity. Williamson maintains that the notion of analytic truth shifts the burden of justification to other classes of notions-necessary truths or logical truths. We have also examined the stipulative notion of analyticity, advanced by Juhl and Loomis. This notion rests on metasemantic facts about language that arguably make trivial its contribution of meaning to truth. The positive result of the meta-semantic strategy is that it avoids the main objections raised against the traditional notion of analyticity but at the cost of reducing analytic judgments to trifling propositions. Finally, we looked at Russell's definition of analyticity as truth in virtue of reference determiner. We have maintained that it avoids many of the standard objections against analyticity. The main objection was that the truth of the expression is always determined by what the world is like. But since we introduced the extension and the reference determiner into meaning that objection became pointless. At the same time, analytic judgments defined this way, retain their epistemically valuable status.

\section{References}

Anderson, R. L. (2005). The Wolffian paradigm and its discontent: Kant's containment definition of analyticity in historical context. Archiv für Geschichte der Philosophie, 87(1), 22-74. http://dx.doi.org/10.1515/agph.2005. 87.1.22

Boghossian, P. A. (1996). Analyticity Reconsidered. Nous, 30(3), 360-391. http://dx.doi.org/10.2307/2216275

Carnap, R. (1947). Meaning and Necessity. Chicago: University of Chicago Press.

Carnap, R. (1967). The Logical Structure of the World and Pseudo problems in Philosophy. (Trans. by R. George). Berkeley: University of California Press.

Dummett, M. (1991). Frege and Other Philosophers. Oxford: Oxford University Press.

Friedman, M. (1999). Logical positivism reconsidered. Cambridge University Press. http://dx.doi.org/10.1017/ CBO9781139173193

Hanna, R. (2007). Kant and the Analytic tradition. In C. V. Boundas (Ed.), Edinburgh Companion to Twentieth-century philosophy. Edinburgh, Edinburgh University Press.

Juhls, C., \& Loomis, E. (2010). Analyticity. London and New-York: Routlege.

Kaplan, D. (1979). On the Logic of Demonstratives. Journal of Philosophical Logic, 8(1), 81-98. http://dx.doi. org/10.1007/BF00258420

Lewis, D. (1970). How to Define Theoretical Terms. Journal of Philosophy, 67, 427-446. http://dx.doi.org/10. $2307 / 2023861$

Proops, I. (2005). Kant's Conception of Analytic Judgment. Philosophy and phenomenological research, LXX(3). http://dx.doi.org/10.1111/j.1933-1592.2005.tb00416.x

Quine, W. V. O. (1951). Two Dogmas of Empiricism. The Philosophical Review, 60(1), 20-43. http://dx.doi.org/ $10.2307 / 2181906$

Rey, G. (2013). The Analytic/Synthetic Distinction. In E. N. Zalta (Ed.), The Stanford Encyclopedia of Philosophy. Retrieved from http://plato.stanford.edu/archives/fall2013/entries/analytic-synthetic/

Russell, G. K. (2008). Truth in virtue of meaning. A Defense of the Analytic/Synthetic Distinction. Oxford University Press. http://dx.doi.org/10.1093/acprof:oso/9780199232192.001.0001

Schroeter, L. (2012). Two-Dimensional Semantics. In E. N. Zalta (Ed.), The Stanford Encyclopedia of Philosophy. Retrieved from http://plato.stanford.edu/archives/win2012/entries/two-dimensional-semantics/

Williamson, T. (2008). The Philosophy of Philosophy. Blackwell, Oxford.

\section{Copyrights}

Copyright for this article is retained by the author(s), with first publication rights granted to the journal.

This is an open-access article distributed under the terms and conditions of the Creative Commons Attribution license (http://creativecommons.org/licenses/by/3.0/). 